\title{
Special issue on International Conference on Microelectronics, Circuits and Systems (Micro 2015), held in Kolkata, India, July, 11-12, 2015
}

\author{
J. K. Mandal ${ }^{1} \cdot$ Dulal Acharjee $^{2} \cdot$ B. Michel $^{3,4}$
}

Published online: 18 August 2017

(C) Springer-Verlag GmbH Germany 2017

The 2nd International Conference on Microelectronics, Circuits and Systems-Micro 2015 was held during 11th to 12 July, 2015 in the Hotel Hyatt Regency in Kolkata, India.

The extended versions of the submitted conference papers were received by Prof. (Dr.) J. K. Mandal, Guest Editor of Micro-2015. He and Prof. D. Acharjee guided the reviewing process of the papers to be published in the Special Issue of the Journal Microsystem Technologies (Springer).

Papers were checked rigorously for incorporation of the criteria specified. The authors were then allowed to upload their paper version into the Springer Microsystem Technology Journal. Each paper we send for double blind review to at least two reviewers selected by the Guest Editors. Based on the suggestions made by the reviewers the articles were revised by the authors and the revised paper versions were scrutinized for incorporation of suggestions of the reviewers and thereafter accepted for publication in the special issue of Micro-2015 in the Springer.microsystem technology journal. 24 papers were ultimately selected for publication.
We would like to thank to esteem reviewers for their efforts to review articles for this special issue.

Hope the articles published in this special issue will be helpful for researchers.

Guest Editors:

Prof. J. K. Mandal, Professor, CSE, University of Kalyani, India

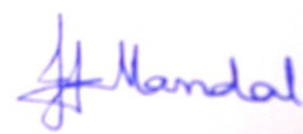

Prof. Dulal Acharjee, President, International Association of Science, Technology and Management, India.

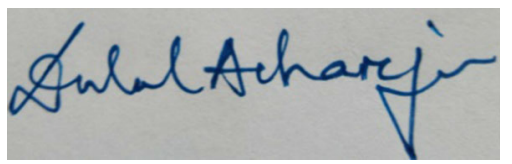

Editor in Chief

Journal Microsystem Technologies

Prof. B. Michel

\footnotetext{
$\triangle$ J. K. Mandal

jkm.cse@gmail.com

Dulal Acharjee

ccsn.micro@gmail.com

B. Michel

office@ coinn.de

University of Kalyani, Kalyani, India

2 IASTM, Kolkata, India

3 Micro Materials Center, Berlin, Germany

4 Micro Materials Center, Chemnitz, Germany
} 